\title{
Effect of duration of pre-operative admission on surgical site infection in major abdominal surgeries: an observational study
}

\author{
Alka Shantiprakash Gupta, Arthika Shetty*
}

Department of Obstetrics and Gynecology, Seth GS Medical College and King Edward Memorial Hospital, Parel, Mumbai, Maharashtra, India

Received: 17 March 2019

Accepted: 04 May 2019

*Correspondence:

Dr. Arthika Shetty,

E-mail: shetty.arthika@gmail.com.

Copyright: (c) the author(s), publisher and licensee Medip Academy. This is an open-access article distributed under the terms of the Creative Commons Attribution Non-Commercial License, which permits unrestricted non-commercial use, distribution, and reproduction in any medium, provided the original work is properly cited.

\begin{abstract}
Background: Surgical site infection (SSI) are second most common cause of mortality in surgical patient, situation has been further complicated by emergence of drug resistant strains. The importance of preventing surgical site infections is well recognized since they lead to increased morbidity, prolonged hospital stays, need for readmission, high end antibiotic treatment and re-surgery. The study was done to see if incidence of SSI is decreased with decreased pre-operative admission time. Others factors associated with SSI were analysed including the microbiological spectrum.

Methods: The study was an analytical, observational, case control study. Sixty (60) cases each of gynaecology and obstetrical post-operative patients who developed SSI within 30 days were taken as cases and who did not develop SSI were taken as controls and preoperative admission time was analysed in both cases and controls to observe if risk of surgical site infections decreases due to decreased exposure to nosocomial pathogens when the pre-operative admission time was less than 48 hours.

Results: Author found that there was statistically significant difference in the time between surgery and admission in the gynaecological surgeries with $\mathrm{p}$ value 0.023 , as compared to the obstetrics surgeries where there was no statistically significant difference. Common organism isolated was E. coli sensitive to gentamicin.

Conclusions: From this study, it seems to be a good policy to evaluate the patient on OPD basis and admit them about 24 to 48 hours prior to the surgery rather them keeping them admitted for prolonged duration in wards for diagnostic evaluation. This prevents nosocomial contamination in the patient's skin flora thereby preventing SSI. This practice not only conserves the hospital resources but also makes the patient turn over faster. Further this might in the long run reduce the antibiotic resistant hospital flora.
\end{abstract}

Keywords: Antibiotics, Drain, Micro organisms, Surgical site infection

\section{INTRODUCTION}

A surgical site infection is infection in part of body where operative intervention has taken place. Post-surgical infection leads to longer duration of hospital stay, increased expenditures, higher rates of readmission and compromised health outcome. ${ }^{1}$ They are the leading cause of nosocomial infections accounting for $40 \%$. $^{2}$
Majority of the surgical site infections are preventable. Care must be taken in the pre-operative, intra-operative and post-operative phases to reduce the risk of surgical site infection. SSI is usually associated with considerable morbidity and it is estimated that one third of postoperative deaths are at least in apart related to SSI. Nosocomial infections are infections occurring more than 48 hours after admission. SSIs are associated with 
considerable morbidity and it has been estimated that one third of the post-operative deaths are at least in a part related to surgical site infections. It can cause significant morbidity almost doubling the duration of hospital stay and thereby increasing economic cost of health care. ${ }^{3}$

Patients with surgical site infections are five times more likely to be readmitted in the hospital, $60 \%$ are more likely to spend time in intensive care unit, and the death rate is twice as compared to patients without infections. ${ }^{4}$

The Center for Disease Control (CDC) defines SSI as an infection related to an operative procedure that occurs at or near the surgical incision within 30 days. This time frame is extended to 12 months if a surgical implant is used. Infections are further divided into:

- Superficial involving skin and subcutaneous tissue

- Deep involving deeper soft tissue of the incision like fascia or muscle

- Organ or space involving any part other than the incised body layers.

Wound scoring done by Southampton scoring system. ${ }^{4}$

\section{Grade and appearance}

- $\quad$ Normal healing

- I-Normal healing with mild bruising or erythema

- Ia-Some bruising

- Ib-Considerable bruising

- $\quad$ Ic-Mild erythema

- II-Erythema plus other signs of inflammation

- IIa-at one point

- IIb-Around sutures

- IIc-Along wound

- IId-Around wound

- $\quad$ III-Clear or hemoserous discharge

- IIIa-at one point only $(\leq 2 \mathrm{~cm})$

- $\quad$ IIIb-Along wound $(>2 \mathrm{~cm})$

- $\quad$ IIIc-Large volume

- $\quad$ IIId-Prolonged (> 3 days)

- IV-Pus

- IVa-At one point only $(\leq 2 \mathrm{~cm})$

- $\quad$ IV b-A long wound $(>2 \mathrm{~cm})$

- V-Deep or severe wound infection with or without tissue breakdown; hematoma

\section{METHODS}

The study was an analytical, observational, case control study. Sixty (60) cases each of gynaecology and obstetrical post-operative patients who developed SSI within 30 days were taken as cases and who did not develop SSI were taken as controls and preoperative admission time was analysed in both cases and controls to observe if risk of surgical site infections decreases due to decreased exposure to nosocomial pathogens when the pre-operative admission time was less than 48 hours.

The study was conducted in Seth G S Medical college hospital - Obstetrics and Gynaecology Department. Postoperative patients were studied, both Obstetrics and Gynaecology cases were taken.

The consent was administered when patient follows up with SSI and data was collected at this time (recruited).

Patient were later followed up once to note the outcome as well as to follow up with the reports of wound culture and sensitivity.

All laparotomies were studied. The study preceded from effect to cause.

\section{Inclusion criteria}

Patients fulfilling the following criteria were included in the study

- $\quad$ Age group $>18$ years $<80$ years

- All clean wounds were considered

- Haemoglobin greater than 8 gm percent

- Patients who were willing to participate in the study and were ready to sign on the written valid informed consent.

\section{Exclusion criteria}

- Presence Patients with addictions to tobacco and alcohol

- $\mathrm{k} / \mathrm{c} / \mathrm{o}$ diabetes mellitus, GDM

- $\mathrm{k} / \mathrm{c} / \mathrm{o}$ Active pulmonary tuberculosis

- Chronic kidney disease

- Chronic liver disease

- Immunocompromised state such as patient on radiotherapy/ on chemotherapy/ oral corticosteroid / seropositive state

- Acute skin infection or known cases of chronic skin disorders

- Patients who were admitted and discharged for investigations one week before actual surgery were not included.

\section{The cases}

- $\quad$ Patients who showed evidence of SSI after 48 hours up to 30 days were included.

- Their previous admission records were analysed regarding their pre-op admission time and other details needed in case record form.

- Post-operative antibiotics received were recorded.

- Local, general and systemic examinations were recorded.

- SSI was categorized based on clinical examination. 
- Wound discharge for culture and sensitivity was collected and traced

- Organisms grown

- Antibiotic culture and sensitivity pattern were noted.

- Need for secondary suturing was also noted.

\section{Controls}

- Random cases at 30 days were taken by convenience sampling. The patients who came for follow up 30 days post operatively and confirmed that there was no SSI after matching the confounding factors (cases leaking per vaginum, meconium stained liquor, pelvic abscess) and who were willing to give their consent were taken a. Their preoperative admission time and other details for the case record was noted

b. Data was statistically analysed using different tests of significance from both the control and case groups using $\mathrm{p}$ value and tests of proportion.

\section{RESULTS}

Table 1, shows that there was statistically significant difference in the time between surgery and admission in the gynaecological surgeries with $\mathrm{p}$ value 0.023 , as compared to the obstetrics surgeries where there was no statistically significant difference with $\mathrm{p}$ value 0.965 (Table 1).

Table 1: Time between surgery and admission.

\begin{tabular}{|llllll|}
\hline Gynaecology & Group & N & Mean & Std. Deviation & P value \\
\hline Time between surgery & Surgical site infection & 30 & 96.30 & 39.285 & \multirow{2}{*}{0.023 statistically significant } \\
\cline { 2 - 5 } and admission (hours) & Control & 30 & 74.40 & 33.031 & \\
\hline Obstetrics & Group & N & Mean & Std. Deviation & P value \\
\hline $\begin{array}{lllll}\text { Time between surgery } \\
\text { and admission (hours) }\end{array}$ & Surgical site infection & 30 & 64.20 & 65.730 & \multirow{2}{*}{0.965} \\
\cline { 2 - 5 } & Control & 30 & 63.13 & 115.335 & \\
\hline
\end{tabular}

Table 2: Body mass index.

\begin{tabular}{|llllll|}
\hline Gynaecology & Group & N & Mean & Std. Deviation & P value \\
\hline \multirow{2}{*}{ Body mass index $\left(\mathrm{kg} / \mathrm{m}^{2}\right)$} & Surgical site infection & 30 & 25.37 & 3.828 & 0.0012 \\
\cline { 2 - 5 } & Control & 30 & 22.00 & 3.238 & Mean \\
\hline \multirow{2}{*}{ Obstretics } & Group & $\mathrm{N}$ & Std. Deviation & P value \\
\hline \multirow{2}{*}{ Body mass index $\left(\mathrm{kg} / \mathrm{m}^{2}\right)$} & Surgical site infection & 30 & 26.47 & 2.788 & \\
\cline { 2 - 5 } & Control & 30 & 22.67 & 3.209 & 0.0001 \\
\hline
\end{tabular}

As seen in Table 2, Body mass index was significantly more in the surgical site infection Group in both obstetrics surgeries and gynaecological surgeries. $\mathrm{P}$ values were statistically significant in both obstetrics as well as gynaecology cases (Table 2).

Table 3: Chief complaint obstetrics SSI cases.

\begin{tabular}{|c|c|c|c|}
\hline Obstetrics & & Count & Column $\mathbf{N} \%$ \\
\hline \multirow{4}{*}{$\begin{array}{l}\text { Chief } \\
\text { complaint }\end{array}$} & Fever & 13 & $43.3 \%$ \\
\hline & Pain & 14 & $46.7 \%$ \\
\hline & Pus discharge & 3 & $10.0 \%$ \\
\hline & Total & 30 & $100.0 \%$ \\
\hline
\end{tabular}

Majority of gynaecology patients with SSI presented with fever as compared obstetrics patients who presented with pain (Table 3, Table 4)

Table 5, 6 shows that $26.7 \%$ of wounds were in Southampton 3B category in gynaecology whereas about
$50 \%$ were in $3 \mathrm{~B}$ category in obstetric surgeries (Table 5, $6)$.

As shown in Figure 1, 2 there was statistically significant difference in the intra operative complication in both obstetrics as well as gynaecology patients; incidence of surgical site infections was significantly higher in patients having intra-operative complications due to higher chances for introduction of microorganism inoculum into surgical site intra-operatively (Figure 1,2).

Table 4: Chief complaint gynaecology SSI cases.

\begin{tabular}{|llll|}
\hline \multicolumn{1}{|c|}{ Gynaecology } & Count & Column N \% \\
\cline { 2 - 4 } & Fever & 15 & $50.0 \%$ \\
\cline { 2 - 4 } Chief & Fever and pus & 1 & $3.3 \%$ \\
\cline { 2 - 4 } complaint & Pain & 7 & $23.3 \%$ \\
\cline { 2 - 4 } & Pain and pus & 5 & $16.7 \%$ \\
\cline { 2 - 4 } & Pus discharge & 2 & $6.7 \%$ \\
\cline { 2 - 4 } & Total & 30 & $100.0 \%$ \\
\hline
\end{tabular}


Table 7 depicts statistically significant difference in the duration of surgery in the two groups in obstetric and gynaecological surgeries with a $p$ value 0.001 and 0.003 respectively. Longer duration of surgeries had significant increase in incidence of surgical site infection in both obstetrics as well as gynaecology cases (Table 7).

Table 5: Southampton wound score: gynaecological surgeries.

\begin{tabular}{|llll|}
\hline Gynaecology & & Count & Column N \% \\
\hline \multirow{5}{*}{$\begin{array}{l}\text { Wound } \\
\text { grade }\end{array}$} & 2C & 3 & $3.3 \%$ \\
\hline & 2D & 1 & $10.0 \%$ \\
\cline { 2 - 4 } & 3B & 8 & $3.3 \%$ \\
\cline { 2 - 4 } & 3C & 4 & $26.7 \%$ \\
\hline & 4D & 3 & $13.3 \%$ \\
\hline & 4B & 6 & $10.0 \%$ \\
\hline & VA & 1 & $6.7 \%$ \\
\hline & V B & 1 & $20.0 \%$ \\
\cline { 2 - 4 } & Total & 30 & $3.3 \%$ \\
\hline
\end{tabular}

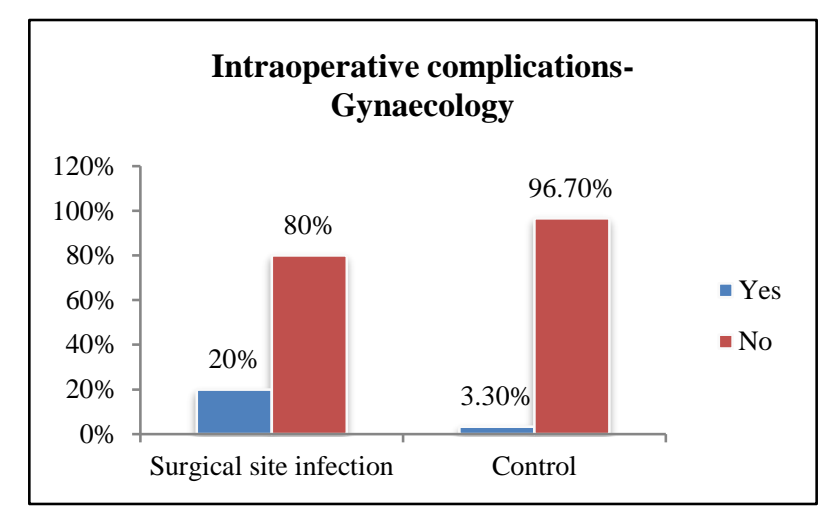

Figure 1: Intra operative complication gynaecological surgeries.



Figure 2: Intra operative complication obstetrics surgeries.

Table 6: Southampton wound score obstetrical surgeries.

\begin{tabular}{|llll|}
\hline Obstetrics & & Count & Column N \% \\
\hline \multirow{5}{*}{$\begin{array}{l}\text { Wound } \\
\text { grade }\end{array}$} & 2B & 4 & $13.3 \%$ \\
\cline { 2 - 4 } & 2C & 2 & $6.7 \%$ \\
\cline { 2 - 4 } & 2D & 2 & $6.7 \%$ \\
\cline { 2 - 4 } & 3B & 7 & $23.3 \%$ \\
\cline { 2 - 4 } & 3C & 4 & $13.3 \%$ \\
\cline { 2 - 4 } & 3D & 2 & $6.7 \%$ \\
\cline { 2 - 4 } & 4B & 1 & $3.3 \%$ \\
\cline { 2 - 4 } & V & 7 & $23.3 \%$ \\
\hline & Total & 30 & $3.3 \%$ \\
\hline
\end{tabular}

As seen in Table 8, there was statistically significant difference in the type of incision in the two groups in gynaecological surgeries with a $\mathrm{p}$ value 0.001 respectively; vertical midline had a higher incidence 26 cases, $86.67 \%$ Table 8 .

Table 7: Duration of surgery.

\begin{tabular}{|llllll|}
\hline Gynaecology & Group & N & Mean & Std. Deviation & P value \\
\hline $\begin{array}{l}\text { Duration of surgery } \\
\text { (hours) }\end{array}$ & Surgical site infection & 30 & 2.633 & .7980 & .001 \\
\cline { 2 - 5 } & Control & 30 & 2.067 & .3651 & P value \\
\hline Obstetrics & Group & $\mathrm{N}$ & Mean & Std. Deviation & .003 \\
\hline $\begin{array}{l}\text { Duration of surgery } \\
\text { (hours) }\end{array}$ & Surgical site infection & 30 & 1.83 & .864 & .391 \\
\cline { 2 - 5 }
\end{tabular}

Table 8: Incision gynaecology.

\begin{tabular}{|clllllll|}
\hline \multirow{2}{*}{ Gynaccology } & \multicolumn{2}{l}{ Surgical site infection } & Control & & \\
\cline { 2 - 8 } & Count & Column N \% & Count & Column N \% & \\
\hline \multirow{3}{*}{ Incision } & Pfannensteil & 4 & $13.33 \%$ & 9 & $30.00 \%$ & P value \\
\cline { 2 - 8 } & Vertical midline & 26 & $86.67 \%$ & 21 & $70.00 \%$ & .001 \\
\cline { 2 - 8 } & Total & 30 & $100.00 \%$ & 30 & $100.00 \%$ & \\
\hline
\end{tabular}


Table 9: Incision during obstetric surgeries.

\begin{tabular}{|cllllll|}
\hline \multirow{2}{*}{ Obstetrics } & \multicolumn{2}{c}{ Surgical site infection } & \multicolumn{1}{c|}{ Control } & & \\
\cline { 2 - 7 } & Count & Column N \% & Count & Column N \% & \\
\hline \multirow{3}{*}{ Incision } & Pfannensteil & 12 & $40.0 \%$ & 8 & $26.7 \%$ & \\
\cline { 2 - 7 } & Vertical midline & 18 & $60.0 \%$ & 22 & $73.3 \%$ & P value \\
\cline { 2 - 7 } & Total & 30 & $100.0 \%$ & 30 & $100.0 \%$ & .001 \\
\hline
\end{tabular}

Table 10: Need for secondary suturing.

\begin{tabular}{|llllllll|}
\hline Gynaecology & & Count & Column N \% & Obstetrics & Count & Column N \% \\
\hline \multirow{3}{*}{ Secondary suturing } & No & 7 & $23.3 \%$ & No & 7 & $23.3 \%$ \\
\cline { 2 - 8 } & Yes & 23 & $76.7 \%$ & Yes & 23 & $76.7 \%$ \\
\cline { 2 - 8 } & Total & 30 & $100 \%$ & Total & 30 & $100.0 \%$ \\
\hline
\end{tabular}

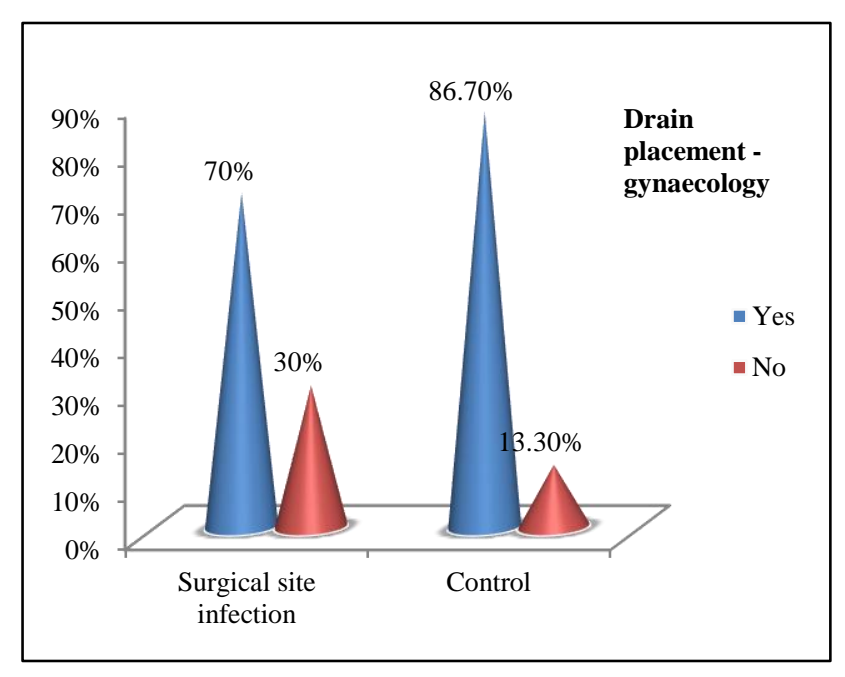

Figure 3: Drain placement gynaecology.

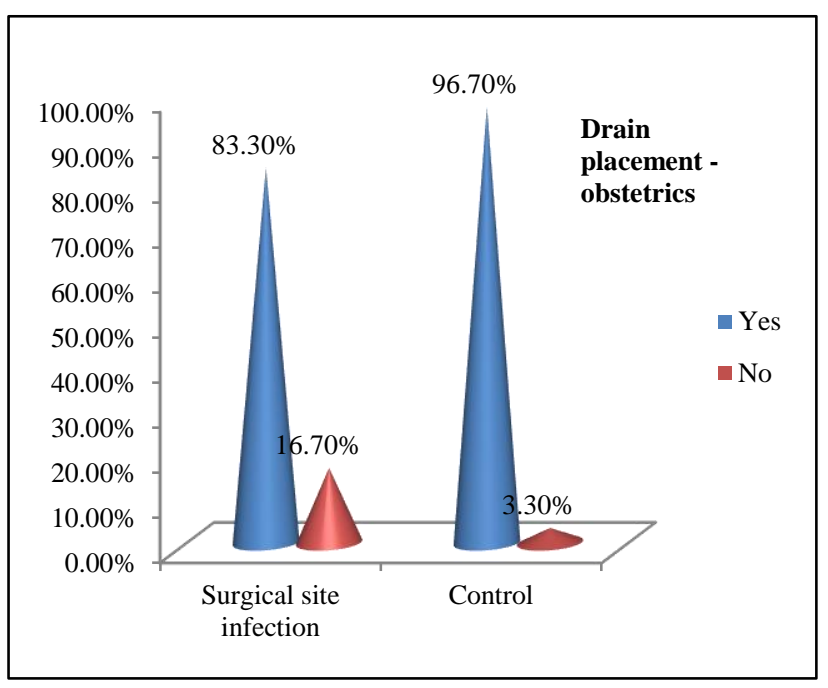

Figure 4: Drain placement obstetrics.

Table 9 shows significant difference in the type of incision in the two groups in obstetric surgeries with a $p$ value 0.001 respectively, Vertical midline had a higher incidence 18 cases $60.0 \%$ (Table 9).
As in Figure 3, 4; incidence of SSI was higher in patients with subcutaneous drains as compared to patient with no drains (Figure3, Figure 4).

As shown in Figure 5, Overall the most common organism was E coli; in 9 cases $(24 \%)$ followed by Pseudomonas aeruginosa in 6 cases (16\%), in the gynaecology group 3 case (17.6) had mixed infections and no mixed infections were seen in the obstetric group. (Figure 5)

As seen in Table 10, in the both the obstetrics group and gynaecology group $23(77 \%)$ needed need for secondary suturing (Table 10)

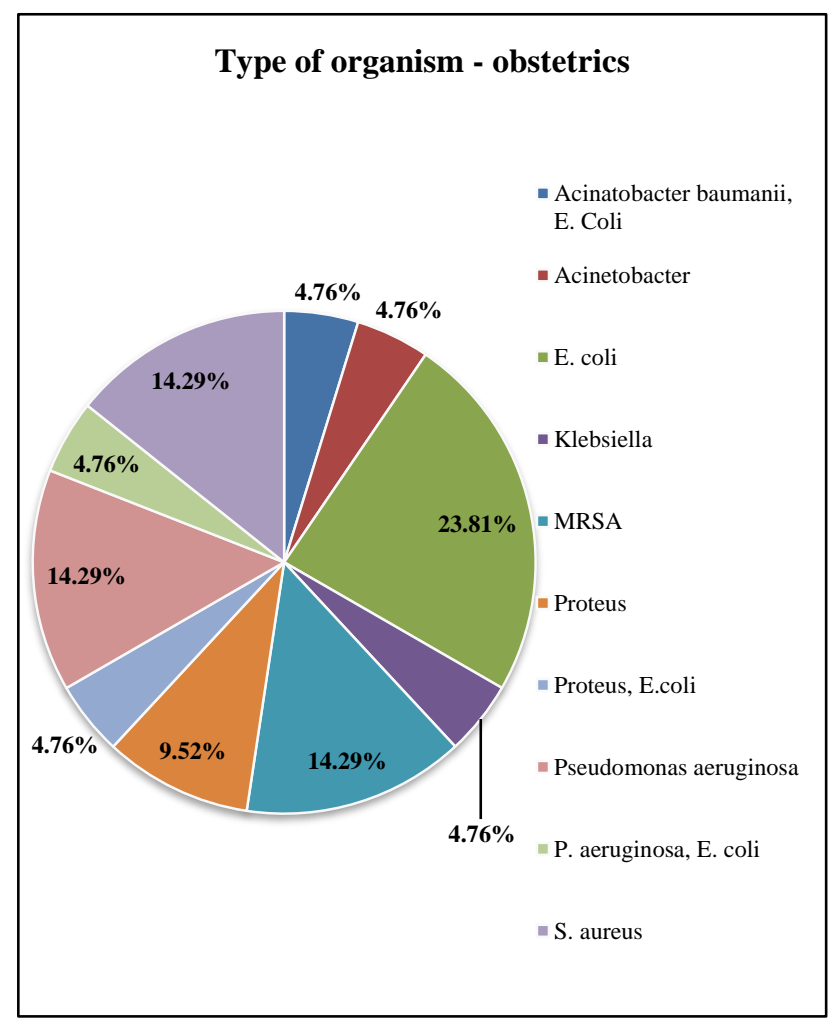

Figure 5: Types of organism. 


\section{DISCUSSION}

Surgical site infection continues to be one of the commonly occurring surgical complication increasing the post-operative morbidity, hospital stay and economic costs. Any surgery is a predisposing factor for hospital acquired infection as it involves breach of the normal defense barrier that is the integrity of the skin and mucous membranes. ${ }^{5}$

There has been a drastic change in the healthcare system in the modern era as compared to the past and field of obstetrics and gynaecology has also experienced the same. A decade ago in the developing countries like India most cases in the field of obstetrics were limited to obstructed labour and/or complicated pregnancies like eclampsia, fetal distress and in gynaecology for ruptured ectopic, procidentia but today it has advanced drastically with expanding indications for LSCS and increase in the rates of abortions especially ectopic sites necessitating surgery, patients opting for hysterectomy even with mild degree of uterine prolapse there has been a pressure on the gynaecologist to do the best especially in times of emergencies.

Surgical complications though unwanted never cease to occur, surgical site infection is one such complication which occurs with a higher incidence in the field of obstetrics and gynaecology as compared to surgeries in other specialities, the probable reasons being caesarean section continues to be one of the commonest surgeries performed by gynaecologist and the surgeries are usually are an emergency where the patient is not optimized

It is quoted in literature that the rates of superficial surgical site infection vary in caesarean section surgeries from $2.5 \%$ to $16 \%$ continuing to be one of the major contributory factor to the post-operative complications. ${ }^{6}$ Even the rates of deep surgical site infection in the form of endometritis ranges from $4 \%, 75 \%$ depending on various factors like the intactness of the amniotic membranes and duration of trial of labour. ${ }^{7}$

The same is also the graph in gynaecological surgeries where surgical site wound infection rate accounts for twelve percent of all gynaecological surgeries. ${ }^{8}$

In our hospital as it is a teaching medical college most cases are referred cases of complicated delivery, failure of induction and even from the gynaecological point of view the cases referred to us are usually those who have various co morbidities which can affect the surgical outcome. Continuous audit of SSIs is an important part of infection control practices of a hospital. Identification of the pathogen and their antibiotic sensitivity pattern is crucial to track the emergent of poly-microbial resistant strains.

Justification for the study was; if the study proves that incidence of SSI is decreased with decreased pre- operative admission time then most of elective cases can be investigated on OPD basis and admitted a day prior to the surgery.

This will substantially decrease the financial burden to a tertiary care government run hospital because of prolonged hospital stay due to SSI and also financial burden of microbiology labs will also be reduced because of expensive wound culture and sensitivity tests.

Incidence of surgical site infection compared to preoperative admission time.

In the present study we found that there was statistically significant difference in the time between surgery and admission in the gynaecological surgeries with $\mathrm{p}$ value 0.023 , as compared to the obstetrics surgeries where there was no statistically significant difference with $\mathrm{p}$ value 0.965. This point to fact that if the patients are admitted less than 48 hours prior to the surgery the incidence of SSI can be reduced drastically and thereby economic burden and also the post-operative morbidity.

The reasons for increase in incidence of surgical site infection in patients admitted about 48 hours prior to the surgery is probably due to contamination of surgical site by microbial inoculum and breech in the aseptic barrier probably due to use of common washrooms in preoperative time, improper hygiene maintenance prior to the surgery. Also, prolonged admission time, multiple examinations by doctors can also introduce nosocomial microbiological inoculum into the patients' flora.

In the present study, $P$ value of 0.965 not stastically significant in obstetric cases this is probably due to emergency nature of surgeries where patients are not fully optimized where multiple host factors account for SSI.

Therefore, by admitting the patients 24 hour prior to the surgery we can avoid this break in aseptic barriers and also prevent the colonisation of the nosocomial flora into the skin of the patient, thereby preventing the SSI and post-operative morbidity as well as hospital expenses due to prolonged admission.

In study conducted by Patel et al, it was postulated that prolonged pre-operative stay leads to colonisation with antimicrobial resistant microorganisms and this in turn affects patients' susceptibility to infection by lowering host resistance or by providing increased opportunity for ultimate bacterial colonisation. $^{9}$

In study conducted by Lilani et al, increase in surgical site infection rate with an increase in preoperative stay also increase in duration of surgery was associated with a significant rise in the rate of surgical site infection. ${ }^{10}$ The most common organism was Staphylococcus Aureus followed by Pseudomonas Aeruginosa. In study 
conducted by Anvikar AR et al, incidence of SSI was increased with increased duration of hospital stay. ${ }^{11}$

\section{BMI}

Various studies have shown that there is a proportional rise in the incidence of SSI with increase of the body fat. In a study by Lake12, and co-workers it was quoted that when the BMI was above 30 or the depth of the fat in the subcutaneous layer was above 3 centimetres the incidence of SSIs rose drastically. In study conducted by Akasaka et al and Kosins et al incidence of SSI was directly proportional to depth of subcutaneous fat.

\section{Chief complaints and clinical signs}

It was found that $50 \%$ of the cases presented with fever followed by pain in $23.3 \%$ in the gynaecological surgeries, and $43.3 \%$ of the cases presented with fever followed by pain in $46.7 \%$ in the obstetrics surgeries

\section{Wound grade}

In the present study $50 \%$ were $3 \mathrm{~B}$ category as per Southampton's scoring system.

In study conducted by Bhadauria et al majority if cases were in Southampton's score $1 .^{13}$

\section{Intr-operative complications}

There was statistically significant difference in the intra operative complication in the two groups in gynaecological as well as obstetric surgeries, incidence of surgical site infections was significantly higher in patients having intra-operative complications due to higher chances for introduction of microorganism inoculum into surgical site intra-operatively. This probably is due faecal or urinary contaminations intraoperatively due to accidental hollow viscus disruptions. As per NICE guidelines incidence of SSI increases by $5 \%$ in patients having intra-operative complications.

\section{Duration of surgery}

There was statistically significant difference in the duration of surgery in the two groups in obstetric and gynaecological surgeries with a p value 0.001 and 0.003 respectively. Longer duration of surgeries had significant increase in incidence of surgical site infection in both obstetrics as well as gynaecology cases this probably again is due increased chances of microbiological inoculum.

In studies conducted by Shahane VD et al, Sutariya PK et al, Razavi SM et al, Satyanarayana V et al, it is observed that incidence of SSI increased with prolonged duration of surgery consistent with the observations in the present study. ${ }^{14-17}$ The reasons postulated for this are:
- With increased operative time the patient's open incision is exposed to the environment for a longer time

- Tissue desiccation is more

- Tissue concentration of antibiotics will decrease as the procedure continues.

However, it is important to remember prolonged surgery may also mean more complex procedures and other intra operative factors like adhesions which by themselves can increase the likelihood of infection

\section{Skin incision}

Vertical incisions are more prone to SSI consistent with results of other studies. Dehiscence may secondary to technical failure of sutures, tension in the suture line, or fascial necrosis due to infections. In study conducted by Mpogoro et al, vertical incisions are three and half times more prone to complications as compared to others. ${ }^{18}$

\section{Placement of drain}

In our study incidence of SSI was more with placement of drain. This result might be biased because all patients with drains had higher BMI; which in itself an important predisposing factor for SSI. In study conducted by cardosiz et al and Kosins et al no relation between placement of drain and SSI. ${ }^{19}$

\section{Types of organisms and culture sensitivity pattern}

Most common organism grown in swab reports in cases of SSI post obstetrics and gynaecology procedure is Ecoli sensitive to gentamicin. In a study conducted by Devjani De et al, the most frequently isolated organism was Acinetobacter species in $32 \%$ followed by Staphylococcus aureus in $22.3 \% .^{9}$ In mild infections, patients were started on Levofloxacin and Metrogyl pending the culture report. In more severe infections Cefotaxime and Metrogyl or Piperacillin/ Tazobactam was started.

World over the most common organism isolated from wound is staphylococcus. Presence of enteric organisms suggests patient's endogenous microbial flora has been contaminated by nosocomial pathogens due to breech in the aseptic barriers. Growth of organisms like E. coli, Pseudomonas aeruginosa usually indicates poor hygiene maintenance. Though strict aseptic precautions are followed as per hospital infection committee guidelines to prevent nosocomial infections, further improvement can be accomplished by decreasing the admission time.

\section{Need for secondary suturing}

In the present study about $76 \%$ of cases (46 out of 60 cases) needed secondary suturing. 
WHO and Center for Disease Control and Prevention guidelines for prevention of surgical site infection (2017) included the following strong recommendations; ${ }^{20,21}$

- $\quad$ Patients are advised to bathe with soap or antiseptic agents at least the night before surgery

- Skin preparation: Hair removal if required is done only by clipping Shaving is strongly discouraged at all times Intra op skin preparation with alcohol-based chlorhexidine gluconate is recommended

- Prophylactic antibiotics should be administered 1 hour before skin incision so that serum and tissue concentration are established before the incision is made. For clean and clean contaminated procedures additional prophylactic antimicrobial agents should not be administered after the surgical incision is closed in the operating room even in a presence of a drain. Topical antimicrobial agents should not be applied on the surgical incision

- Protocols for peri-operative glycaemic control to be implemented using blood glucose target level of $<200 \mathrm{mg} / \mathrm{dl}$ in patients with or without diabetes

- Peri-operative normothermia should be maintained in all patients. Increased fraction of inspired oxygen should be administered during surgery and after extubation in the immediate postoperative period for patients with normal pulmonary function undergoing general anaesthesia.

\section{CONCLUSION}

In conclusion to this study, we found that there was increased rate of surgical site infection in the patients admitted prior to 48 hours in gynaecological cases whereas incidence was not increased in obstetrics cases. From this study, it seems to be a good policy to evaluate the patient on OPD basis and admit them about 24 to 48 hours prior to the surgery rather them keeping them admitted for prolonged duration in wards for diagnostic evaluation. This prevents nosocomial contamination in the patient's skin flora thereby preventing SSI. This practice not only conserves the hospital resources but also makes the patient turn over faster.

Further this might in the long run reduce the antibiotic resistant hospital flora. Prevention of SSI is an important part of providing optimum care for patients. Throughout the world there is a growing concern about patient safety. This prompted the WHO to launch the World Alliance for patient safety. Continuous audit and implementation of infection prevention strategies should part of the standard protocols of every hospital.

\section{ACKNOWLEDGMENTS}

Authors would like to thank Dean of KEM Hospital for his support during study.
Funding: No funding sources

Conflict of interest: None declared

Ethical approval: The study was approved by the Institutional Ethics Committee

\section{REFERENCES}

1. Barie PS, Eachempati SR. Surgical clinics of North America; 2005;85(6):1115-35.

2. Mangram AJ, Horan TC, Pearson ML. Guideline for prevention of surgical site infection, 1999. Hospital infection control practices advisory committee. Infect Control Hosp Epidemiol. 1999;20(4):250-78.

3. Surgical site infection: Prevention and Treatment of Surgical Site Infection NICE Clinical Guidelines, No. 74, National Collaborating Centre for Women's and Children's Health(UK). London: RCOG Press; 2008.

4. Bailey IS, Karran SE, Toyn K, Brough P, Ranaboldo C, Karran SJ. Southampton wound scoring system. BMJ. 1992;304(6825):469-71.

5. Olsen MA, Butler AM, Willers DM. Risk factors for surgical site infection after low transverse ce U.S., 1990-2003. Obstet Gynecol. 2008;112(6):1235-41.

6. Joyce AM, Hamilton BE, Sutton PD, Births: Final Data for 2005. National Vital Statistics Report. 2007;56:6.

7. Owen J, Andrews WW. Wound complications after caesarean sections. Clin Obstet Gynecol. 1994;37:842.

8. Tita, Alan TN. Emerging Concepts in in antibiotic prophylaxis for caesarean delivery. Obstetrics Gynaecol. 2009;13(3):675-82.

9. Patel SM, Patel MH, Patel SD, Soni ST, Kinariwala DM, Vegad MM. Surgical site infections: incidence and risk factors in a tertiary care hospital, western India. National J Comm Med. 2012;3(2).

10. Lilani SP, Jangale N, Chowdhary A, Daver GB. Surgical site infection in clean and cleancontaminated cases. Indian $\mathbf{J}$ Med Microbiol. 2005;23:249-52.

11. Anvikar AR, Deshmukh AB, Karyakarte RP, Damle AS, Patwardhan NS, Malik AK, et al. A one-year prospective study of 3,280 surgical wounds. Indian J Med Microbiol. 1999;17:129-3.

12. Lake AG, McPencow AM, Dick-Biascoechea MA, Martin DK, Erekson EA. Surgical site infection after hysterectomy. Am J Obstet Gynecol. 2013;209(5):490 e491-490 e499.

13. Bhadauria AR., Hariharan C. Clinical study of postoperative wound infections in obstetrics and gynaecological surgeries in a tertiary care set up. Int J Reprod Contracept Obstet Gynecol. 2013;22(4):631-8.

14. Shahane VD, Bhawal S, Lele U. Surgical site infections: a one year prospective study in a tertiary care center. International J Health Sci. 2012;23;6(1).

15. Sutariya PK, Chavada MV. Incidence and determinants of the surgical site infection: a hospital based longitudinal study. Int Surg J. 2016;3:2202-6. 
16. Razavi SM, Ibrahimpoor M, Kashani AS, Jafarian A. Abdominal surgical site infections: incidence and risk factors at an Iranian teaching hospital. BMC Surgery. 2005;5(1):1.

17. Satyanarayana V, Prashanth HV, Bhandare B, Kavyashree AN. Surgical site infection in abdominal surgeries. J Clin Diagn Res. 2011;5(5):935-9.

18. Mpogoro. Incidence and predictors of surgical site infections following caesarean sections at Bugando Medical Centre, Mwanza, Tanzania. Antimicrobial Resist Infect Cont. 2014;3:25.

19. Cardosi RJ, Drake J, Holmes S. Subcutaneous management of vertical incisions with 3 or more centimeters of subcutaneous fat. Am J Obstet Gynecol. 2006;195(2):607-14.

20. WHO-Global Guidelines for the Prevention of Surgical Site Infection. World Health Organization.
ISBN $97892 \quad 4 \quad 154988$ 2. Available at: http://www.who.int/infection-prevention/publications /ssi-prevention-guidelines/en/.

21. Berríos-Torres SI, Umscheid CA, Bratzler DW, Leas B, Stone EC, Kelz RR, et al. Centres for disease control and prevention guideline for the prevention of surgical site infection. JAMA Surg. 2017;152(8):784-91.

Cite this article as: Gupta AS, Shetty A. Effect of duration of pre-operative admission on surgical site infection in major abdominal surgeries: an observational study. Int J Reprod Contracept Obstet Gynecol 2019;8:2306-14. 